\title{
基于“多规合一”的市级国土空间优化方法 以烟台市为例
}

\author{
张骏杰 ${ }^{1}$, 高延利 ${ }^{2}$, 蔡玉梅 ${ }^{2}$, 周 伟 ${ }^{1}$, 袁 涛 $^{1}$
}

(1. 中国地质大学(北京)土地科学技术学院, 北京 $100083 ; 2$. 中国土地勘测规划院, 北京 100035)

\begin{abstract}
摘 要: 针对现阶段各规划边界交叉、空间重叠的问题,本文从提高空间价值、减少空间破碎度和协调各类空间的角 度出发,在梳理现有空间优化模型及智能算法的基础上, 改进多目标规划模型并适应性改造遗传算法, 以此二者构 建市级国土空间优化模型。以烟台市为例, 设置 3 种情景为决策者提供方案集进行 3 类规划主导下的 2020 年国土 空间优化研究,结果显示: (1)优化后烟台市农业、城镇和生态空间价值分别增加了 23.24\%、29.27\%、6.30\%; 2)不同 情景下空间分布合理且较为集中,生态保护情景有利于国土空间集合连片,经济发展情景更适合于多空间协调发 展。研究表明: 该模型能有效地解决国土空间内容重叠问题, 明显提高了国土空间价值, 同时优化模型适应性强, 为“多规合一”背景下市级国土空间优化提供技术支撑。
\end{abstract}

关 键 词:多规合一; 国土空间优化;多目标规划模型; 遗传算法; 烟台市

\section{1 引言}

国土空间是国家政治、经济、文化活动的场所 (肖金城等, 2012), 也是城镇化的载体(林坚等, 2016), 随着中国经济快速增长, 工业化城镇化推 进, 现已进人转型发展的新阶段(刘彦随等, 2016)。 然而各规划部门分割管理、自划边界, 不同的规划 体系和技术标准致使各类国土空间边界交叉、内容 重叠, 部门之间 “摩擦打架” 的问题日益严重, 已呈 现出 “多级多类” 的规划格局(黄勇等, 2016)。习近 平总书记在党的十八大和中央城镇化工作会议中 提出, 要“建立统一的空间规划体系、限定城市发展 边界、划定生态红线, 在县(市)探索经济社会发展、 城乡、土地利用规划等的 “三规合一, 或 ‘多规合 一, 。”因此, 如何解决各部门交叉冲突区域的边界 调整, 建立科学有序的空间规划体系 (喻锋等, 2014; 㚞杰, 2016), 是推进“多规合一”、实现国土空 间优化配置的重点与难点。
针对空间的优化方法学者们早已开始研究,传 统的数学规划模型如线性规划(陈国良等, 1983; Kent et al, 1991)有效地进行了数量结构的优化, 然 而无法配置到空间上。地理信息技术的发展为空 间优化提供了重要支持(罗鼎等, 2009; 谢正峰等, 2011), 现阶段将 GIS 与智能优化算法结合(Stewart et al, 2014; Gharbia et al, 2016), 实现区域土地数量 结构优化与空间优化的统一已成为学者的研究热 点。马世发等(2010)将粒子群算法用于城镇土地利 用空间优化,验证了粒子群算法在统一优化土地利 用数量结构和空间结构中的有效性; 袁满等(2014) 构建多智能体模型辅助遗传算法, 对武汉市蔡甸区 进行土地利用优化配置。以上研究对区域土地利 用空间优化配置进行了方法探索, 然而国土空间涉 及大量复杂的空间信息, 需要考虑到国土资源的自 然属性和社会经济状况以及空间的系统性和多层 次特性, 是一个多目标非线性组合优化问题(王红 瑞等, 2008; 黄迎春等, 2016)。因此,有必要运用多

收稿日期: 2017-08-24; 修订日期 : 2018-03-09。

基金项目: 国家国际科技合作专项(2015DFA01370) [Foundation: International Scientific and Technological Cooperation Program of China, No.2015DFA01370]。

作者简介: 张骏杰(1992-), 男, 江苏无锡人,硕士研究生, 主要从事空间规划相关研究, E-mail: zchieh@163.com。

通讯作者:蔡玉梅(1970-), 女, 辽宁铁岭人,博士, 研究员, 主要研究方向为土地利用评价与规划, E-mail: caiyumei@263.net。 
目标规划模型并辅以智能算法进行国土空间优化。

多目标优化模型最早由美国经济学家 V.Pareto 提出, 用于解决目标相互冲突或者度量单位不一致 的问题。该模型是一个由目标函数与约束条件组 合而成的框架, 结构简单灵活。自提出以来, 刘耀 林等学者将其成功应用到空间优化领域(刘耀林 等, 2011; 张鸿辉等, 2011), 但仍然局限于土地利用 空间优化, 其本质为土地用途的调整。而国土空间 优化是从空间的多功能或价值的属性出发, 综合考 虑空间功能之间的协调问题, 从而对空间布局进行 合理的调整。现阶段尚未见“多规并存”条件下国 土空间的优化研究。

遗传算法作为智能算法, 具有较强的全局寻优 和空间搜索能力, 其适应度函数能与多目标规划模 型有效结合, 因此可用于模型的求解。针对国土空 间的特点,本文在多目标规划模型的基础上丰富其 内容, 同时相应地改造遗传算法, 二者结合构建国 土空间优化方法, 以烟台市为例, 模拟在不同情景 下(冯仕超等, 2013; 张丁轩等, 2013)冲突区域的国 土空间优化配置, 以期为 “多规合一” 背景下的市级 国土空间优化提供科学方案。

\section{2 市级国土空间优化方法}

\section{1 优化模型及尺度确定}

由于在进行国土空间优化时会同时考虑多种 目标, 故本文采用多目标规划模型进行空间优化, 模型包括目标函数和约束体系两部分。学者们在 运用多目标规划模型进行研究时, 以经济效益和空 间成片布局为目标, 本文结合 “多规合一” 背景下国 土空间的特点, 丰富经济效益目标内容从而形成国 土空间价值模型, 同时新增空间协调度模型以满足 不同国土空间之间地理相关性需求。

首先, 多数规划集中在省级、市级以及县乡级, 省级规划为控制性规划, 难以用模型进行定量测 算; 县乡级规划较少, 同时由于行政区划易发生变 更导致时间不连续; 市级规划尺度上各类规划较为 详细，同时划分结果导致国土空间重叠问题严重。 其次, 市级规划数据齐全且比较规范, 因此选取市 级尺度进行优化方法的研究。

\subsection{1 目标函数}

本文目标函数包含 3 类模型, 不仅考虑各类国 土空间冲突区域价值的最大化, 而且考虑优化结果
在空间上的布局合理性。假设研究区内共 $K$ 种国 土空间,栅格化处理后形成 $M \times N$ 个空间单元。

(1) 国土空间价值模型

以各空间价值最大化为目标, 分别采用不同指 标进行空间价值度量：

$$
A=\sum_{k=1}^{K} \omega_{k} \overline{f_{k}}
$$

式中: $A$ 为国土空间价值目标函数; $\bar{f}_{k}$ 代表国土空 间类型为 $k$ 时归一化后的价值; $\omega_{k}$ 是相对应的权重 系数。

(2) 空间布局紧凑度模型

空间布局紧凑度用于避免优化后空间单元分 散,引导相同空间单元成片分布,计算方法如下:

$$
B=\sum_{k=1}^{K} \sum_{i=1}^{N} \sum_{j=1}^{M} b_{i j k} \cdot X_{i j k}
$$

式中: $B$ 为空间布局紧凑度模型目标函数; $b_{i j k}$ 为某个 国土空间单元领域聚集度变量,用空间类型为 $k$ 的 邻域中相同空间单元的个数表示; $X_{i j k}$ 为二元变量, 当 单元 $(i, j)$ 为国土空间类型 $k$ 时, 值为 1 , 否则取值 0 。

(3) 空间协调度模型

一种空间单元的变化由自身和环境共同决定， 因此考虑到相邻空间单元布置时所形成的生产、生 活等方面的舒适程度, 用协调度表征两相邻空间之 间的协调性：

$$
C=\sum_{i=1}^{N} \sum_{j=1}^{M} c_{i j}
$$

式中: $C$ 为空间协调度模型目标函数; $c_{i j}$ 为某国土空 间单元与其相邻单元的协调度, 根据地方特点选取 相应指标进行测算。

$$
\operatorname{Max} F=\psi_{1} \bar{A}+\psi_{2} \bar{B}+\psi_{3} \bar{C}
$$

针对上述 3 类模型进行加权统一为总目标函数 的方法。式(4)中: $\bar{A} 、 \bar{B} 、 \bar{C}$ 为归一化后的目标函 数值; $\psi_{1}, \psi_{2}, \psi_{3}$ 为对应的权重; $F$ 为适宜度目标, 值 越大则该空间优化方案越优。

\subsection{2 约束体系}

在空间优化的过程中, 为使结果与当地实际情 况或者土地政策相符,本文设定以下几种约束条件 来避免无限制的优化过程。在优化前后，国土空间 总面积保持不变; 各类国土空间指标各自不得低于 一定量; 每个国土空间单元且只能配置一种空间类 型, 确保每种优化方案的唯一性:

$$
\begin{gathered}
\sum_{k=1}^{K} S_{k}=S_{0} \\
\forall \varepsilon_{k} \geqslant T_{k}
\end{gathered}
$$




$$
\sum_{k=1}^{K} X_{i j k}=1
$$

式中: $S_{k}$ 为某种国土空间类型的面积; $S_{0}$ 为优化后总 面积; $\varepsilon_{k}$ 为某国土空间优化后指标; $T_{k}$ 为对应的指标 下限。

\section{2 国土空间优化算法}

遗传算法(Cao et al, 2012)是一种模拟遗传定律 不断进行种群迭代的智能化算法, 由于其适应度函 数值与多目标规划模型目标函数能完美融合, 因此 选用遗传算法并进行适应性改造作为国土空间优 化算法。如图 1 所示, 初始过程中将各空间图层转 为 ascii 码作为遗传算法的输人数据, 在初始空间布 局图集生成的情况下开始进行适应度评价, 适应度 函数值由模型目标函数求得, 是进行遗传操作的评 价标准。选择、交叉和变异算子依据终止条件不断 进行迭代直至最优解的产生, 最后输出国土空间布 局方案。针对国土空间的特点以及优化模型的目 标, 本文在传统的交叉算子和变异算子基础上进行 相应改进。

\subsection{1 交叉算子}

交叉运算用于生成具有上一代特征的新染色

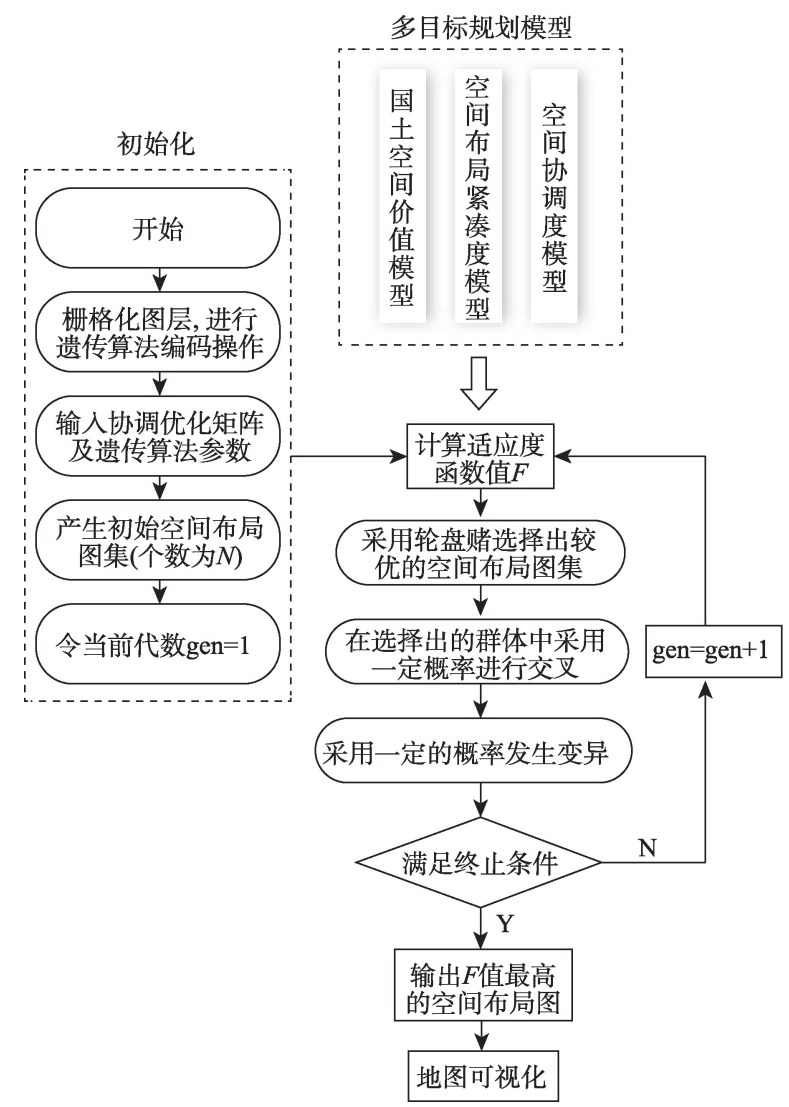

图 1 算法流程图

Fig.1 Flowchart of the algorithm
体,染色体代表某次运算后的某一空间图层。如图 2 所示, 被选为交叉的染色体随机确定 2 个具有相 同位置的空间单元, 将染色体 $1 \mathrm{a}$ 与染色体 $2 \mathrm{a}$ 的 2 个 交叉点之间的空间单元进行交叉互换形成染色体 $1 \mathrm{~b}$ 和染色体 $2 \mathrm{~b}$ 。由此可以避免传统遗传算法中单 点交叉运算导致子代与父代染色体差异过大的 问题。

\subsection{2 变异算子}

为防止遗传算法陷人局部最优, 需对种群以很 小的变异率随机改变所选染色体的基因值, 以产生 新染色体。为降低优化后空间破碎的概率, 如图 3 所示,在进行变异运算时,采用郭小燕等(2015)的混 合蛙跳算法思路将被选中的空间单元取值向邻域 8 个单元中数量占优的基因转变。

\begin{tabular}{|c|c|c|c|c|c|c|c|c|c|c|c|c|c|c|}
\hline 0 & 0 & 2 & 2 & 2 & 3 & 3 & 3 & 0 & 0 & 2 & 22 & $\begin{array}{lll}2 & 3 \\
\end{array}$ & 3 & 3 \\
\hline 0 & 0 & 1 & 1 & 3 & 3 & 3 & 3 & 0 & 0 & 1 & \begin{tabular}{l|l}
1 & 3
\end{tabular} & \begin{tabular}{l|l}
3 & 3
\end{tabular} & 3 & 3 \\
\hline 0 & 0 & 1 & 1 & 3 & 2 & 2 & 2 & 0 & 0 & 1 & 13 & $\begin{array}{ll}3 & 2 \\
\end{array}$ & 2 & 2 \\
\hline 0 & 2 & 1 & 1 & 1 & 2 & 2 & 2 & 0 & 2 & 2 & \begin{tabular}{l|l}
2 & 2
\end{tabular} & $\begin{array}{lll}2 & 3\end{array}$ & 3 & 3 \\
\hline 1 & 1 & 1 & 1 & 1 & 3 & 2 & 2 & 1 & 1 & 2 & 22 & \begin{tabular}{l|l}
2 & 3 \\
\end{tabular} & 3 & 3 \\
\hline 1 & 2 & 2 & 2 & 3 & 3 & 3 & 2 & 1 & 1 & 2 & 22 & \begin{tabular}{l|l}
2 & 3
\end{tabular} & 3 & 2 \\
\hline 1 & 2 & 2 & 2 & 3 & 3 & 2 & 2 & 1 & 2 & 2 & \begin{tabular}{l|l}
2 & 3
\end{tabular} & \begin{tabular}{l|l}
3 & 3 \\
\end{tabular} & 2 & 2 \\
\hline 1 & 1 & 2 & \begin{tabular}{l|l}
3 \\
\end{tabular} & 3 & 3 & 0 & 0 & 1 & 1 & 2 & \begin{tabular}{l|l}
3 & 3 \\
\end{tabular} & \begin{tabular}{l|l}
3 & 3 \\
\end{tabular} & 0 & 0 \\
\hline \multicolumn{8}{|c|}{ 染色体1a } & \multicolumn{7}{|c|}{ 染色体1b } \\
\hline 0 & 0 & 1 & 1 & 2 & 2 & 2 & 2 & 0 & 0 & 1 & 1 & \begin{tabular}{l|l}
2 & 2 \\
\end{tabular} & 2 & 2 \\
\hline 0 & 0 & 1 & 1 & 3 & 3 & 3 & 3 & 0 & 0 & 1 & 1 & \begin{tabular}{l|l}
3 & 3 \\
\end{tabular} & 3 & 3 \\
\hline 0 & 0 & 1 & 1 & 1 & 1 & 3 & 3 & 0 & 0 & 1 & \begin{tabular}{l|l}
1 & 1 \\
\end{tabular} & \begin{tabular}{l|l}
1 & 1 \\
\end{tabular} & 3 & 3 \\
\hline 0 & 2 & 2 & 2 & 2 & 3 & 3 & 3 & 0 & 2 & 1 & 1 & \begin{tabular}{l|l}
1 & 2 \\
\end{tabular} & 2 & 2 \\
\hline 1 & 1 & 2 & 2 & 2 & 3 & 3 & 3 & 1 & 1 & 1 & 1 & \begin{tabular}{l|l|}
1 & 3 \\
\end{tabular} & 2 & 2 \\
\hline 1 & 1 & 2 & 2 & 2 & 3 & 3 & 3 & 1 & 2 & 2 & 2 & \begin{tabular}{l|l}
3 & 3
\end{tabular} & 3 & 3 \\
\hline 1 & 1 & 1 & 2 & 2 & 3 & 3 & 3 & 1 & 1 & 1 & 2 & \begin{tabular}{l|l}
2 & 3 \\
\end{tabular} & 3 & 3 \\
\hline 1 & 1 & 1 & 1 & 3 & 3 & 0 & 0 & 1 & 1 & & & \begin{tabular}{l|l}
3 & 3 \\
\end{tabular} & 0 & 10 \\
\hline
\end{tabular}

图 2 交叉算子

Fig.2 Crossover operator

\begin{tabular}{|c|c|c|c|c|c|c|c|c|c|c|c|c|c|c|c|}
\hline 0 & 0 & 2 & 2 & 2 & 3 & 3 & 3 & 0 & 0 & 2 & 2 & 2 & 3 & 3 & 3 \\
\hline 0 & 0 & 1 & 1 & 3 & 3 & 3 & 3 & 0 & 0 & 1 & 1 & 3 & 3 & 3 & 3 \\
\hline 0 & 0 & 1 & 1 & 3 & 2 & 2 & 2 & 0 & 0 & 1 & 1 & 1 & 2 & 2 & 2 \\
\hline 0 & 2 & 1 & 1 & 1 & 2 & 2 & 2 & 0 & 2 & 1 & 1 & 1 & 2 & 2 & 2 \\
\hline 1 & 1 & 1 & 1 & 1 & 3 & 2 & 2 & 1 & 1 & 1 & 1 & 1 & 3 & 2 & 2 \\
\hline 1 & 2 & 2 & 2 & 3 & 3 & 3 & 2 & 1 & 2 & 2 & 2 & 3 & 3 & 3 & 2 \\
\hline 1 & 2 & 2 & 2 & 3 & 3 & 2 & 2 & 1 & 2 & 2 & 2 & 3 & 3 & 2 & 2 \\
\hline 1 & 1 & 2 & 3 & 3 & 3 & 0 & 0 & 1 & 1 & 2 & 3 & 3 & 3 & 0 & 0 \\
\hline
\end{tabular}

图 3 变异算子

Fig.3 Mutation operator 


\section{3 研究区及数据}

\section{1 研究区概况}

烟台市位于山东半岛最东北部(图 4), 东西长约 $214 \mathrm{~km}$ 、南北宽约 $130 \mathrm{~km}$, 北濒黄、渤海, 与大连隔 海相望, 具有非常便利的海、陆、空交通条件, 优越 的地理位置使得烟台成为 “一带一路”国家战略重 点建设港口城市。2015 年, 全市共辖 7 个区、8 个县 级市、 81 个建制镇、 67 个街道办事处, 总面积为 $13746 \mathrm{~km}^{2}$, 年末户籍总人口 701.41 万人, 其中城镇 人口 423.30 万人。 2015 年实现地区生产总值 6446.08 亿元, 较上年增长 $8.4 \%$, 其中第一产业增加 值 440.85 亿元, 第二产业增加值 3323.46 亿元, 第三 产业增加值 2681.77 亿元。烟台市现有的主要规划 有土地利用总体规划、城市总体规划和生态保护红 线规划, 然而各部门从自身发展目标出发进行规划 的结果导致城市建设用地扩张、耕地面积增加及生 态保护红线外延之间产生矛盾冲突, 因此亟待进行 空间优化。

\section{2 数据来源}

土地利用数据包括 2014 年土地利用现状数据 (比例尺为 $1: 20$ 万)、基本农田分布图和农用地分等 定级图, 主要源于烟台市土地利用总体规划(20062020 年); 城镇发展和生态保护数据分别从烟台市 城市总体规划(2011 年-2020年)及烟台市生态保护 红线规划(2016-2020年)中获取; 统计数据来自烟台 市统计年鉴(2005 年-2015 年), 主要包括粮食产量、 GDP 及粮食作物播种面积等社会经济统计数据。

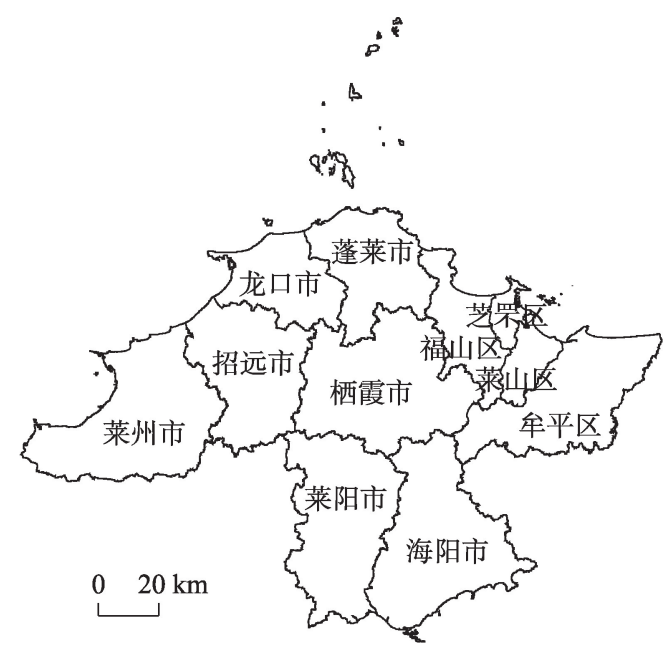

图4 烟台市行政区划图

Fig.4 Administrative divisions of Yantai City

\section{3 数据处理}

将土地利用总体规划数据、城市总体规划数据 和生态保护红线数据进行矢量化处理, 以此 3 类规 划处理得到的数据分别表征农业空间、城镇空间和 生态空间(表1),而水域、道路及规划范围以外研究 区范围内的其他国土空间将作为不变内容不参与 本研究。考虑到研究精度和算法运行效率, 经过多 次调试, 确定栅格单元大小为 $200 \mathrm{~m} \times 200 \mathrm{~m}$, 栅格化 处理后研究区共计 578908 个单元。

\section{4 烟台市国土空间优化研究}

\section{1 变量与模型}

\subsection{1 变量设置}

通过上文可知烟台市主要为土地利用总体规 划、城市总体规划和生态保护红线规划 3 类,由此划 分出的国土空间产生重叠, 本文选取农业空间、城 镇空间和生态空间之间相互冲突的区域作为优化 的内容。由于处理后的数据中每类空间分为 2 类, 共6种空间类型。其中农业空间中的基本农田根据 国家法律不能改变功能,城镇空间中的建成区通常 难以改变为其他空间,生态空间中的禁止开发区也 不能改变功能。因此,参与冲突优化的空间有 3 种 空间类型,形成的冲突类型有 4 种, 需先设定协调规 则篮选出参与优化的变量, 再采用本文构建的优化 模型和算法进行优化(图 5)。

\section{表 1 各类国土空间内容}

Tab.1 Spatial planning contents in this study

\begin{tabular}{|c|c|c|}
\hline 国土空间 & 主要内容 & 与三规对照 \\
\hline $\begin{array}{l}\text { 农业 } \\
\text { 空间 }\end{array}$ & $\begin{array}{l}\text { 以提供农产品服务为主,满足人 } \\
\text { 类基本生存的空间。根据土地 } \\
\text { 利用总体规划、基本农田分布图 } \\
\text { 及农用地分等定级图划分为基 } \\
\text { 本农田及一般耕地。其中包括 } \\
\text { 零星的农村建设用地等。 }\end{array}$ & $\begin{array}{l}\text { 土地利用总体规划 } \\
\text { 的基本农田保护区、 } \\
\text { 一般农地区及自然 } \\
\text { 保留地等 }\end{array}$ \\
\hline $\begin{array}{l}\text { 城镇 } \\
\text { 空间 }\end{array}$ & $\begin{array}{l}\text { 以提供工业品或服务产品为主, } \\
\text { 促进人类发展进步的空间。以 } \\
\text { 城镇建设用地为主, 根据各县城 } \\
\text { 市总体规划划分为建成区及拓 } \\
\text { 展区域。 }\end{array}$ & $\begin{array}{l}\text { 城市总体规划的居 } \\
\text { 住用地、商业服务业 } \\
\text { 设施用地及工业用 } \\
\text { 地等 }\end{array}$ \\
\hline $\begin{array}{l}\text { 生态 } \\
\text { 空间 }\end{array}$ & $\begin{array}{l}\text { 以提供生态系统服务为主, 保障 } \\
\text { 社会可持续发展的空间。根据 } \\
\text { 生态保护红线规划重新划分为 } \\
\text { 禁止开发区及二级管控区。包 } \\
\text { 括农用地中的非耕地等。 }\end{array}$ & $\begin{array}{l}\text { 生态保护红线规划 } \\
\text { 的结果,包括 } \\
\text { 生态保护红线区和I } \\
\text { 类红线区 }\end{array}$ \\
\hline
\end{tabular}

注:其他细小分类根据其主导功能或提供的主要服务划分为相 应国土空间。 
协调后每类国土空间均发生了变化,所涵盖的 内容具有多层空间属性, 本文将协调后的各国土空 间作为模型变量(表 2)参与优化。

\subsection{2 模型输人}

优化模型的 3 类子模型中, 空间布局紧凑度模 型和空间协调度模型为市级国土空间优化通用模 型，而国土空间价值模型需针对地方国土空间特点 进行测算。烟台市国土空间价值模型以农业空间、 城镇空间和生态空间的价值最大化为目标, 分别采 用不同指标进行空间价值度量：

$$
\begin{gathered}
f_{\mathrm{AU}}=\sum_{k=1}^{K} C_{k} \cdot S_{k} \cdot P_{k} \\
f_{\mathrm{US}}=\sum_{k=1}^{K} V_{k} \cdot S_{k} \\
f_{\mathrm{ES}}=\sum_{k=1}^{K} E_{k} \cdot S_{k} \\
A=\omega_{1} \overline{f_{\mathrm{AS}}}+\omega_{2} \overline{f_{\mathrm{US}}}+\omega_{3} \overline{f_{\mathrm{ES}}}
\end{gathered}
$$

式中: $f_{\mathrm{AS}} 、 f_{\mathrm{US}}$ 和 $f_{\mathrm{ES}}$ 分别为农业空间、城镇空间和生 态空间价值; $C_{k}$ 为第 $k$ 种粮食单位面积产量; $P_{k}$ 为第 $k$ 种粮食市场收购价格; $S_{k}$ 代表各类国土空间面积;
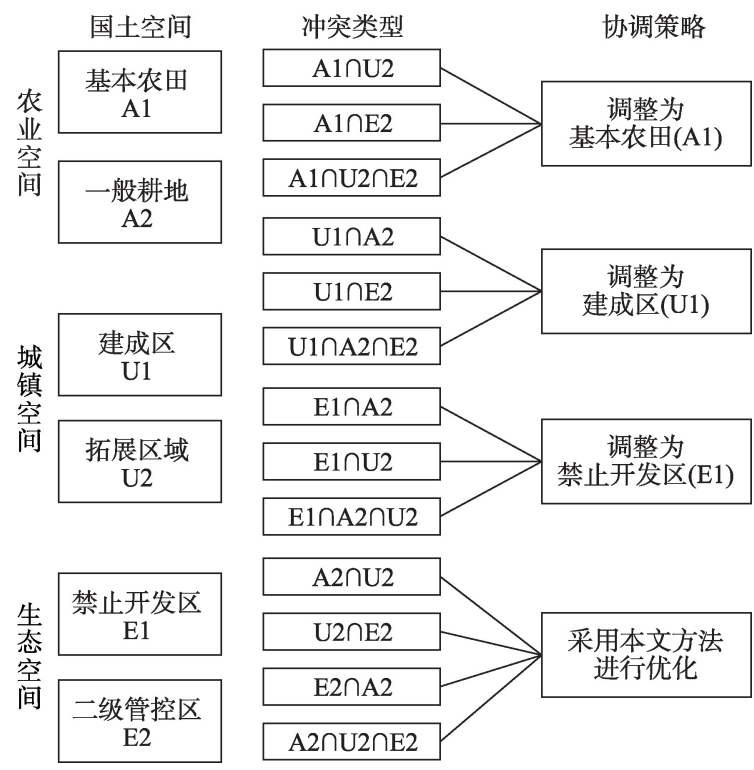

注: 1. 禁止开发区包括自然保护区、森林公园等法定保护区; 2.2 种 空间冲突的内容不包含 3 种空间同时冲突。

图 5 空间优化协调规则

Fig.5 Coordination rules of spatial optimization

表2 各类国土空间变量设置

Tab.2 Spatial planning variable settings in this study

\begin{tabular}{cl}
\hline 变量 & \multicolumn{1}{c}{ 内容 } \\
\hline 农业空间 & 与其他空间冲突的一般耕地 \\
城镇空间 & 与其他空间冲突的拓展区域 \\
生态空间 & 与其他空间冲突的二级管控区 \\
\hline
\end{tabular}

$V_{k}$ 为国内生产总值, 分别离散到各乡镇尺度上(胡云 锋等, 2011; 李飞等, 2014); $E_{k}$ 为单位面积生态系统 服务价值量, 参考谢高地等(2015)学者构建的生态 系统服务价值评估方法, 并对烟台地区进行了区域 性系数修正(修正系数 1.38)(谢高地等, 2005)。为了 使空间布局与价值属性相对应, 将各类空间价值进 行预测(姚作芳等, 2010; 喻胜华等, 2016)并统一到 目标年即 2020 年, 最后将 3 类价值加权统一。

\section{2 多情景模拟}

考虑到烟台市国土空间现状及社会经济发展 战略,本文设定粮食安全、经济发展和生态保护 3 种 情景进行不同优先发展目标下的国土空间布局优 化。粮食安全情景的目的在于优先保证耕地质量 和数量, 提高粮食产量; 经济发展情景以保障建设 用地为核心, 考虑新型城镇化下经济发展的需求; 生态保护情景考虑对具有基础性生态服务功能土 地的保护,包括生态脆弱区及生态敏感区等。多情 景模拟对空间优化模型的目标函数产生影响, 从而 导致多种空间布局方案, 为实际应用提供方案集。 其中不同情景对于空间优化模型的影响体现在空 间价值模型及空间协调度模型的参数设定上。针 对不同的情景目标,本文通过征询土地、生态等相 关领域专家的意见,并结合当地规划部门建议,采 用专家打分法确定了不同国土空间价值模型中的 权重(表3)。

根据空间协调度模型和烟台市特征, 设定空间 优化协调矩阵(表 4)。粮食安全情景下,农业空间与

表3 不同情景下权重设置

Tab.3 Weights of variables under different scenarios

\begin{tabular}{cccc}
\hline 变量 & 粮食安全 & 经济发展 & 生态保护 \\
\hline 农业空间价值权重 $\omega_{1}$ & 0.5 & 0.4 & 0.3 \\
城镇空间价值权重 $\omega_{2}$ & 0.2 & 0.5 & 0.1 \\
生态空间价值权重 $\omega_{3}$ & 0.3 & 0.1 & 0.6 \\
\hline
\end{tabular}

\begin{tabular}{|c|c|c|c|c|c|c|c|c|c|}
\hline \multirow{2}{*}{ 国土空间 } & \multicolumn{3}{|c|}{ 粮食安全情景 } & \multicolumn{3}{|c|}{ 经济发展情景 } & \multicolumn{3}{|c|}{ 生态保护情景 } \\
\hline & AS & US & ES & AS & US & ES & AS & US & ES \\
\hline AS & 1.0 & 0.6 & 0.8 & 1.0 & 0.8 & 0.6 & 1.0 & 0.4 & 0.8 \\
\hline US & 0.6 & 1.0 & 0.4 & 0.8 & 1.0 & 0.4 & 0.4 & 1.0 & 0.4 \\
\hline ES & 0.8 & 0.4 & 1.0 & 0.6 & 0.4 & 1.0 & 0.8 & 0.4 & 1.0 \\
\hline
\end{tabular}

表 4 烟台市不同情景下空间优化协调矩阵

Tab.4 Coordination matrix of spatial optimization under different scenarios in Yantai City

注: 矩阵外 AS、US、ES 分别表示: AS 农业空间, US 城镇空间, ES 生态空间; 矩阵内: 数值表示空间之间协调系数,矩阵行表示正 向协调性,列表示逆向协调性。 
生态空间协调性最高, 保证粮食可持续生产; 经济 发展情景下, 城镇空间与农业空间协调性最高, 保 证经济发展; 生态安全情景下, 生态空间与农业空 间协调性最高, 以防止生态被破坏。任何情景下空 间自协调性最高, 为 1 , 而城镇空间与生态空间呈负 相关性,协调性最低。

\section{5 结果与分析}

\section{1 优化结果}

利用优化模型及遗传算法对烟台市进行国土 空间优化, 算法参数如下: 种群大小 50 , 迭代次数 100 , 交叉概率 0.7 , 变异概率 0.02 。优化前后价值对 比见表 5。将迭代寻优得到的最优解进行可视化处 理, 分别得到 2020 年烟台市粮食安全、经济发展和

表 5 优化前后价值对比

Tab.5 Comparison of land values before and after optimization

\begin{tabular}{cccc}
\hline 国土空间 & 优化前价值/元 & 优化后价值/元 & 增幅 $/ \%$ \\
\hline 农业空间 & $9.47 \times 10^{8}$ & $1.17 \times 10^{9}$ & 23.24 \\
城镇空间 & $8.80 \times 10^{9}$ & $1.14 \times 10^{10}$ & 29.27 \\
生态空间 & $6.06 \times 10^{7}$ & $6.44 \times 10^{7}$ & 6.30 \\
\hline
\end{tabular}

注: 优化后价值为 3 种情景下的加权平均值。
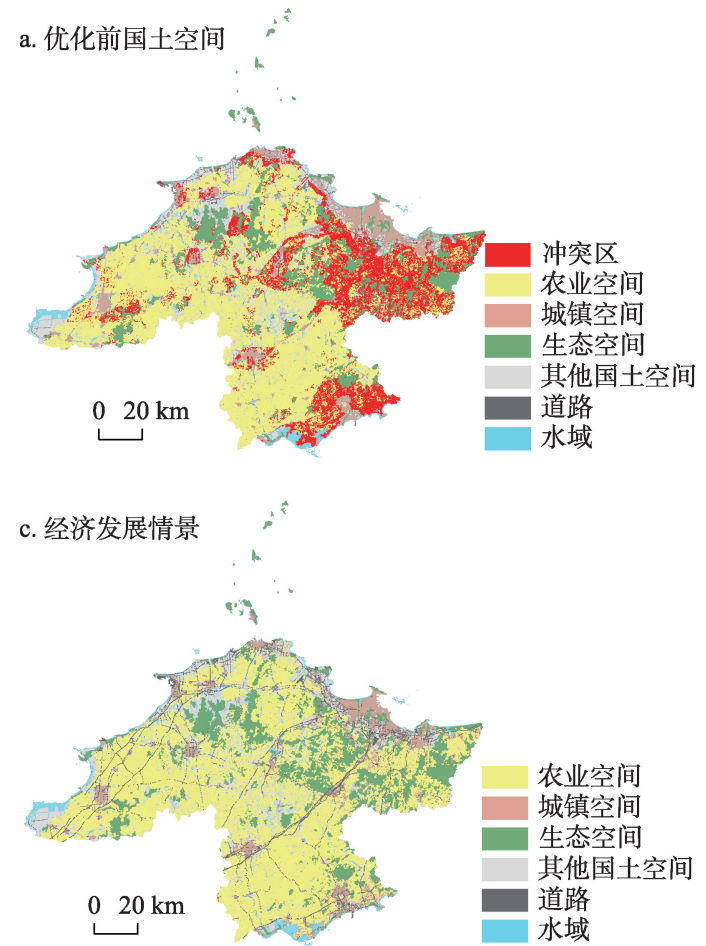

生态保护情景下的国土空间优化结果(图 6)。

结合表 5 和图 6 可以看出, 优化后国土空间无 冲突区域且分布较为连片集中,不同情景下 3 类国 土空间面积的变化符合不同优先目标下的空间分 布原则 ; 同时优化后农业、城镇和生态空间价值增 幅为 $23.24 \% 、 29.27 \% 、 6.30 \%$, 与烟台市统筹城乡经 济与产业,推进国民经济健康发展, 全面提升农业 综合生产能力, 严格保护生态环境的规划目标相一 致, 可认为优化结果有效。

\section{2 不同情景下各类空间优化结果分析}

基于各类国土空间优化前后范围以及所产生 空间价值的变化, 分别从粮食安全、经济发展和生 态保护 3 种情景分析烟台市国土空间优化结果。

（1）粮食安全情景下,农业空间的面积为 490167 $\mathrm{hm}^{2}$, 所产生的价值为 $1.16 \times 10^{9}$ 元, 主要分布在莱州 市东北、招远市中部以及莱阳市与海阳市的交界 处,成片程度较高。如图 6b 所示, 新增农业空间集 中在莱州市中部及莱阳市的南部, 由于该区域地势 平坦,水利条件良好,有可改造的中、低产田以及蔬 菜生产基地, 因此被优化为农业空间的概率较大。 城镇空间面积为 $93467 \mathrm{hm}^{2}$, 优化后价值的增幅与 农业空间基本持平(为 $25.89 \%$ ), 新增空间分布在沿 海县市的市区边界处。生态空间面积为 236646
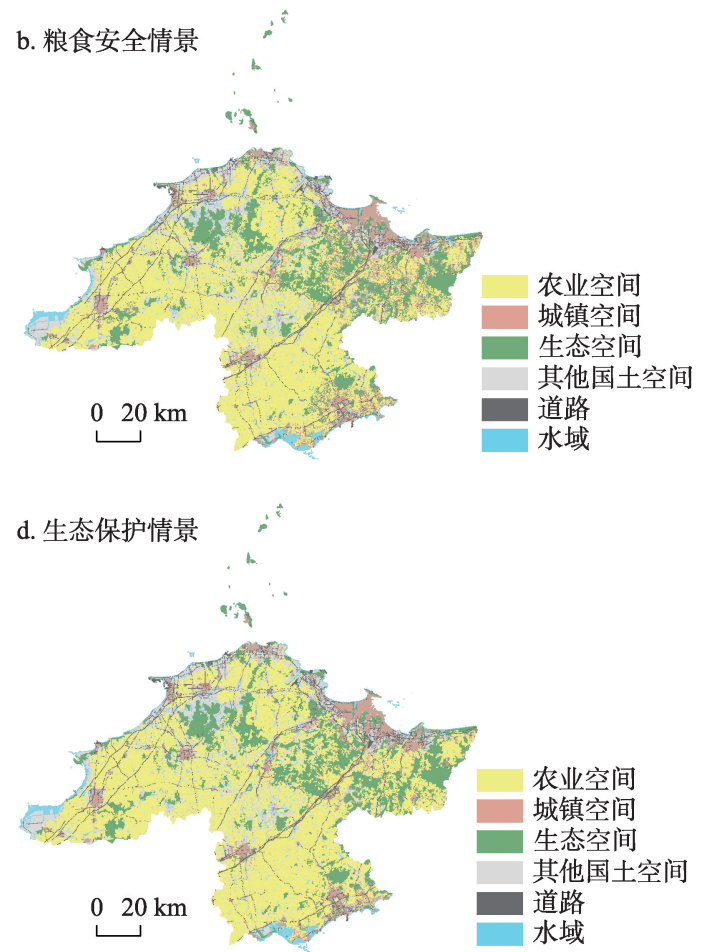

图 6 不同情景下 2020 年烟台市优化前后国土空间格局

Fig.6 Land Space of Yantai City before and after optimization under different scenarios in 2020 
$\mathrm{hm}^{2}$, 价值增幅最低为 $8.16 \%$, 生态空间扩张趋势较 为缓和。总体来看, 与经济发展和生态安全情景相 比,该情景下 3 类空间发展较为均衡。

(2) 经济发展情景下, 城镇价值提升至 $1.17 \times$ $10^{10}$ 元, 相比于粮食安全情景提升了 $8.21 \%$, 同时面 积比粮食安全情景增加了 $1035 \mathrm{hm}^{2}$, 达到 3 种情景 中的最高值。如图 $6 \mathrm{c}$, 新增城镇空间主要集中在芝 罟区及海阳市区的城市边界附近, 呈向外拓展的趋 势, 还有一部分分布在交通条件发达的区域,整体 上呈组团式发展。该情景下粮食产量也得到了显 著提升, 相比于粮食安全情景, 农业价值增加了 $5.59 \times 10^{6}$ 元, 面积却减少 $8.10 \mathrm{hm}^{2}$, 主要是由于粮食 安全情景通过保证耕地的数量和质量而实现; 经济 发展情景以经济效益为优先目标, 在优化过程中保 留高标准农田, 将部分产量较低的农业空间转为其 他具有更高相对价值的国土空间, 使得面积增幅略 小, 但价值却增幅较大。生态空间由于经济效益较 低,面积几乎无变化, 价值仅提高了 $1.56 \%$ 。在该情 景下, 随着城镇化的推进, 烟台市城市扩张最为明 显, 土地得到了高效利用并带动农业空间发展, 一 定程度制约了生态空间的发展。

(3) 生态安全情景下, 烟台市生态空间变化最 明显, 所产生的价值为 $6.62 \times 10^{7}$ 元, 面积增加至 $236795 \mathrm{hm}^{2}$, 主要集中在研究区东北部的山区以及 蓬莱港区和芝罢湾港区, 而新增生态空间分布在栖 霞市与福山区交界处的丘陵地带以及昆崩山保护 区周围(图 6d)。相比于粮食安全和经济发展情景, 农业价值和城镇价值增幅下降了 $0.78 \%$ 和 6.62\%， 面积增幅分别下降了 $97.70 \mathrm{hm}^{2}$ 及 $1150.70 \mathrm{hm}^{2}$ 。由 此可见该情景受政策影响较大, 起到了建设地方生 态文明的作用,符合国家“十三五”规划要求。

\section{3 单位空间分析}

为了进一步评价分析不同情景的适用性, 采用 单位空间价值、单位紧凑度和单位协调度 3 个指数 来评价不同情景之间的结果差异情况。单位空间 价值反映了某种国土空间类型在单位面积上所产 生价值的高低, 值越高表明越适合该国土空间的发 展, 反之则可发展程度越低; 单位紧凑度描述同一 类型国土空间聚合程度, 紧凑度越高表明该国土空 间越集中成片, 反之越破碎; 单位协调度表征了不 同国土空间之间耦合状况, 值越高表明国土空间之 间关联越稳定, 反之则越容易分散。3 种指标采用 目标函数中的国土空间价值(A)、空间布局紧凑度 (B)以及空间协调度 $(C)$ 与单元个数之比求得 $($ 表 6$)$ 。
表 6 不同情景下优化结果分析

Tab.6 Optimization results under different scenarios

\begin{tabular}{cccccc}
\hline \multirow{2}{*}{ 情景 } & \multicolumn{3}{c}{ 单位空间价值/元 } & \multicolumn{2}{c}{ 单位 } \\
\cline { 2 - 5 } & $\begin{array}{c}\text { 单位 } \\
\text { 业空间 }\end{array}$ & 城镇空间 & 生态空间 & 紧凑度 & 协调度 \\
\hline 粮食安全 & 53981 & 511913 & 2981 & 1.5508 & 2.3744 \\
经济发展 & 53235 & 533450 & 2799 & 1.5629 & 2.5245 \\
生态保护 & 52902 & 506920 & 3008 & 1.5876 & 2.2228 \\
\hline
\end{tabular}

从单位空间价值看,农业空间、城镇空间以及 生态空间价值分别在粮食安全、经济发展和生态保 护情景下达到最高, 符合目标优先的原则, 在所有 情景中城镇价值、农业价值及生态价值依次递减, 表明烟台市以推进城镇化为优先目标的同时兼顾 耕地和生态环境的保护。从单位紧凑度看,生态保 护情景下空间聚合程度最高,减缓了生境破碎化问 题,促进国土空间向“双核、一带、多轴”的景观格局 发展。而经济发展情景下单位协调度最高, 保证各 空间融合发展。

\section{6 结论与讨论}

本文跳出土地利用优化的局限性,针对多类空 间冲突优化改进了多目标规划模型, 目标函数包括 空间价值、空间紧凑度和空间协调度 3 个子模型。 同时借鉴前人思路改造了遗传算法中交叉算子和 变异算子,形成国土空间优化算法。二者结合形成 市级国土空间优化方法, 以烟台市为例, 设置粮食 安全、经济发展和生态保护 3 种情景进行实证研究, 利用不同情景下优化后的空间范围和空间价值变 化分析优化结果, 并利用单位空间价值、紧凑度和 协调度分析不同情景的适用性。主要结论如下:

(1) 本文构建的研究方法解决了烟台市土地利 用总体规划、城市总体规划以及生态保护红线规划 导致的国土空间冲突问题,优化后农业、城镇和生 态空间价值分别提升了 $23.24 \%$ 、29.27\% 和 6.30\%。 从变化范围的视角来看,不同国土空间扩张存在明 显差异, 其中城镇空间扩张程度最大, 表明烟台市 未来以推进新型城镇化为主。

(2) 通过对不同情景下各类空间优化结果的分 析可以看出, 烟台市各类空间的价值差异符合情景 设置的优先目标, 不同情景下国土空间优化结果的 差异与研究区实地情况相符,粮食安全情景适合于 3 类空间均衡发展的模式, 经济发展情景提供了以 推动城镇化为主要目标的多空间融合方案, 生态保 
护情景则有利于实现生态文明建设, 上述 3 种情景 为烟台市未来城市发展提供了重要参考。通过对 单位空间指标的研究发现, 生态保护情景下单位紧 凑度最高, 有利于空间集中连片, 而经济发展情景 更适合于多空间协调发展。

(3) 统一行使所有国土空间用途管制是新时代 中国生态文明建设的新举措。按“多规合一”的要 求编制国家、省和市县级国土空间规划是落实用途 管制的基础。而市县级国土空间规划具有实施性 和操作性, 因此是进行国土空间优化的最佳尺度。 探索市县级国土空间优化方法, 优化国土空间格 局, 提升国土空间功能, 可以为促进国民经济的高 质量发展提供支撑, 也可为中国即将开展的国土空 间规划工作提供参考。

本文采用多目标规划模型与遗传算法结合的 研究方法合理地优化了各类空间规划范围, 促进国 土空间布局与数量结构的有效配置, 国土空间价值 得到有效提高, 为多主体规划的冲突问题提供了一 种解决思路; 同时国土空间价值模型可根据地方特 点选取指标进行测算, 适应性强, 因此可为 “多规合 一”背景下市级国土空间优化提供技术支撑。

目前针对 “多规合一”的研究仍处于理论探索 阶段,虽然本文构建了国土空间优化方法并成功应 用到研究区, 然而仍存在一些明显的不足之处。首 先, 本文初步尝试了各类国土空间内容的界定以及 定量化的表达, 但仍存在一些具有争议的用地难以 进行分类, 因此如何科学完善空间分类体系并选取 适宜的度量指标对于国土空间优化的研究尤为关 键。另外,本文空间协调矩阵虽然结合研究区特征 进行设置, 然而实际上多个空间之间的协调程度不 仅与地理因素相关, 人类活动或者政策因素等都会 产生影响, 因此如何定量化不同空间之间正负反馈 关系也是今后进一步研究的内容。

\section{参考文献(References)}

陈国良, 刘笃慧. 1983. 黄土丘陵区农林牧合理生态经济结 构模式的初步研究 [J]. 植物生态学与地植物学丛刊, 7 (3): 215-221. [Chen G L, Liu D H. 1983. A preliminary study on the rational eco-economic structure model of agriculture, forestry and animal husbandry in the Loess Hilly Regions $[\mathrm{J}]$. Acta Phytoecologica et Geobotanica Sinica, 7 (3): 215-221.]

柇杰. 2016. 我国国土空间开发保护格局优化配置理论创新 与 “十三五”规划的应对策略 [J]. 中国科学院院刊, 31(1):
1-12. [Fan J. 2016. Theoretical innovation in optimization of protection and development of China's territorial space and coping strategy of 13th Five- Year Plan[J]. Bulletin of Chinese Academy of Sciences, 31(1): 1-12.]

冯仕超, 高小红, 顾娟, 等. 2013. 基于 CLUE-S 模型的湟水流 域土地利用空间分布模拟[J]. 生态学报, 33(3): 985-997. [Feng S C, Gao X H, Gu J, et al. 2013. Land use spatial distribution modeling based on CLUE- $\mathrm{S}$ model in the Huangshui River Basin[J]. Acta Ecologica Sinica, 33(3): 985-997.]

郭小燕, 刘学录, 王联国. 2015. 基于混合蛙跳算法的土地利 用格局优化 [J]. 农业工程学报, 31(24): 281-288. [Guo X Y, Liu X L, Wang L G. 2015. Land use pattern optimization based on shuffled frog leaping algorithm[J]. Transactions of the Chinese Society of Agricultural Engineering, 31(24): 281-288.]

胡云锋, 王倩倩, 刘越, 等. 2011. 国家尺度社会经济数据格 网化原理和方法 $[\mathrm{J}]$. 地球信息科学学报, 13(5): 573-578. [Hu Y F, Wang Q Q, Li Y, et al. 2011. Index system and transferring methods to build the national society and economy grid database[J]. Journal of Geo-Information Science, 13(5): 573-578.]

黄迎春, 杨伯钢, 张飞舟, 等. 2016. 基于同类城市建设目标 的北京市土地利用结构优化 [J]. 农业工程学报, 32(4): 217-227. [Huang Y C, Yang B G, Zhang F Z, et al. 2016. Optimization of land use structure in Beijing based on goal of similar city in world[J]. Transactions of the Chinese Society of Agricultural Engineering, 32(4): 217-227.]

黄勇, 周世锋, 王琳, 等. 2016. “多规合一”的基本理念与技 术方法探索 [J]. 规划师, 32(3): 82-88. [Huang Y, Zhou S F, Wang L, et al. 2016. Basic theory and technique of multi-plans integration[J]. Planners, 32(3): 82-88.]

李飞, 张树文, 杨久春, 等. 2014. 社会经济数据空间化研究 进展 [J]. 地理与地理信息科学, 30(4): 102-107. [Li F, Zhang S W, Yang J C, et al. 2014. A review on research about spatialization of socioeconomic data[J]. Geography and Geo-Information Science, 30(4): 102-107.]

林坚, 柳巧云, 李婧怡. 2016. 探索建立面向新型城镇化的国 土空间分类体系 [J]. 城市发展研究, 23(4): 51-60. [Lin J, Liu Q Y, Li J Y. 2016. Research on establishing a land space utilization classification for new urbanization[J]. Urban Development Studies, 23(4): 51-60.]

刘彦随, 王介勇. 2016. 转型发展期“多规合一”理论认知与 技术方法 [J]. 地理科学进展, 35(5): 529-536. [Liu Y S, Wang J Y. 2016. Theoretical analysis and technical methods of "multiple planning integration" in the rural to urban transition period in China[J]. Progress in Geography, 35 (5): 529-536.] 
刘耀林, 洪晓峰, 刘殿锋, 等. 2011. 利用模拟退火算法的村 镇土地利用空间优化调控模型 [J]. 武汉大学学报: 信息 科学版, 36(6): 752-755. [Liu Y L, Hong X F, Liu D F, et al. 2011. Optimal spatial regulation model for village and town land-use based on simulated annealing[J]. Geomatics and Information Science of Wuhan University, 36(6): 752755.]

罗鼎, 许月卿, 邵晓梅, 等. 2009. 土地利用空间优化配置研 究进展与展望[J]. 地理科学进展, 28(5): 791-797. [Luo D, Xu Y Q, Shao X M, et al. 2009. Advances and prospects of spatial optimal allocation of land use[J]. Progress in Geography, 28(5): 791-797.]

马世发, 何建华, 俞艳. 2010. 基于粒子群算法的城镇土地利 用空间优化模型 [J]. 农业工程学报, 26(9): 321-326. [Ma S F, He J H, Yu Y. 2010. Model of urban land-use spatial optimization based on particle swarm optimization algorithm[J]. Transactions of the Chinese Society of Agricultural Engineering, 26(9): 321-326.]

王红瑞, 张文新, 胡秀丽, 等. 2008. 土地利用区间数多目标 规划模型及其应用 [J]. 农业工程学报, 24(8): 68-73. [Wang H R, Zhang W X, Hu X L, et al. 2008. Model of interval multi-objective programming of land-use and its application[J]. Transactions of the Chinese Society of Agricultural Engineering, 24(8): 68-73.]

肖金成, 欧阳慧. 2012. 优化国土空间开发格局研究[J]. 经济 学动态, (5): 18-23. [Xiao J C, Ouyang H. 2012. Youhua guotu kongjian kaifa geju yanjiu[J]. Economic Perspectives, (5): 18-23.]

谢高地, 肖玉, 甄霖, 等. 2005. 我国粮食生产的生态服务价 值研究 [J]. 中国生态农业学报, 13(3): 10-13. [Xie G D, Xiao Y, Zhen L, et al. 2005. Study on ecosystem services value of food production in China[J]. Chinese Journal of Eco-Agriculture, 13(3): 10-13.]

谢高地, 张彩霞, 张雷明, 等. 2015. 基于单位面积价值当量 因子的生态系统服务价值化方法改进 [J]. 自然资源学 报, 30(8): 1243-1254. [Xie G D, Zhang C X, Zhang L M, et al. 2015. Improvement of the evaluation method for ecosystem service value based on per unit area[J]. Journal of Natural Resources, 30(8): 1243-1254.]

谢正峰, 董玉祥. 2011. 我国城市土地优化配置研究演进与 展望[J]. 经济地理, 31(8): 1364-1369. [Xie Z F, Dong Y X. 2011. Evolution and prospect of China's research on the urban land optimal allocation[J]. Economic Geography, 31 (8): 1364-1369.]

姚作芳, 刘兴土, 杨飞. 2010. 马尔科夫方法修正的灰色模型 在吉林省粮食产量预测中的应用 [J]. 地理科学, 30(3): 452-457. [Yao Z F, Liu X T, Yang F. 2010. Application of grey model modified by Markov method in the yield prediction of Jilin Province[J]. Scientia Geographica Sinica, 30(3): 452-457.]

喻锋, 张丽君, 李晓波, 等. 2014. 国土空间开发及格局优化 研究: 现状述评、战略方向、技术路径与总体框架 [J]. 国 土资源情报, (8): 41-46. [Yu F, Zhang L J, Li X B, et al. 2014. Research on spatio-land development and its pattern optimization: Status- quo review, strategic orientations, technology paths and overall framework[J]. Land and Resources Information, (8): 41-46.]

喻胜华, 龚尚花. 2016. 基于 Lasso 和支持向量机的粮食价格 预测 [J]. 湖南大学学报: 社会科学版, 30(1): 71-75. [Yu S H, Gong S H. 2016. A study on grain price prediction based on Lasso and support vector machine[J]. Journal of Hunan University: Social Sciences, 30(1): 71-75.]

袁满, 刘耀林. 2014. 基于多智能体遗传算法的土地利用优 化配置 [J]. 农业工程学报, 30(1): 191-199. [Yuan M, Liu Y L. 2014. Land use optimization allocation based on multi-agent genetic algorithm[J]. Transactions of the Chinese Society of Agricultural Engineering, 30(1): 191-199.]

张丁轩, 付梅臣, 陶金, 等. 2013. 基于 CLUE-S 模型的矿业城 市土地利用变化情景模拟 [J]. 农业工程学报, 29(12): 246-256. [Zhang D X, Fu M C, Tao J, et al. 2013. Scenario simulation of land use change in mining city based on CLUE-S model[J]. Transactions of the Chinese Society of Agricultural Engineering, 29(12): 246-256.]

张鸿辉, 曾永年, 刘慧敏. 2011. 多目标土地利用空间优化配 置模型及其应用 [J]. 中南大学学报: 自然科学版, 42(4): 1056-1065. [Zhang H H, Zeng Y N, Liu H M. 2011. Multiobjective spatial optimization model for land use allocation and its application[J]. Journal of Central South University: Science and Technology, 42(4): 1056-1065.]

Cao K, Huang B, Wang S, et al. 2012. Sustainable land use optimization using Boundary-based Fast Genetic Algorithm [J]. Computers Environment and Urban Systems, 36(3): 257-269.

Gharbia S S, Alfatah S A, Gill L, et al. 2016. Land use scenarios and projections simulation using an integrated GIS cellular automata algorithms[J]. Modeling Earth Systems and Environment, 2(3): 151.

Kent B, Bare B B, Field R C, et al. 1991. Natural resource land management planning using large- scale linear programs: The USDA Forest Service experience with FORPLAN[J]. Operations Research, 39(1): 13-27.

Stewart T J, Janssen R. 2014. A multiobjective GIS-based land use planning algorithm[J]. Computers Environment and Urban Systems, 46(7): 25-34. 


\title{
Spatial optimization on the municipal level based on "multiple planning integration": A case study of Yantai City
}

\author{
ZHANG Junjie', GAO Yanli², CAI Yumei ${ }^{2 *}$, ZHOU Wei', YUAN Tao ${ }^{1}$ \\ (1. School of Land Science and Technology, China University of Geosciences, Beijing 100083, China; \\ 2. China Land Surveying and Planning Institute, Beijing 100035, China)
}

\begin{abstract}
With the rapid economic growth and the advancement of industrialization and urbanization, China has entered into a new stage of transformation and development since the economic reform and opening- up. However, due to the sectoral management by various planning departments, different planning system and technical standards present a phenomenon of boundary crossing and spatial overlap in the land space. How to solve the problem of boundary adjustment in conflict area caused by different planning and establish a scientific and orderly spatial planning system have become important and difficult issues. Because a large amount of complex spatial information is involved in spatial planning, we also need to consider the natural and socioeconomic attributes of land space. Therefore, spatial planning under such circumstances becomes a multiobjective optimization problem for nonlinear combinations. Traditional mathematical models such as linear programming and grey linear programming cannot meet this requirement. But the development of geographic information technology provides important support for spatial optimization. Scholars have combined mathematical models with the algorithm to explore the quantitative structure and spatial optimization of regional land space. Yet, these studies essentially take land use into consideration, ignoring the systematic and hierarchical nature of land space. In addition, they have mainly considered land use planning or master urban planning but not considered the optimization of various land spatial conflicts under different planning schemes. On the basis of existing spatial optimization models and intelligent algorithm, a model of land spatial optimization with both multi-objective programming and genetic algorithm has been constructed in this study. This model aims to improve the spatial value, reduce the degree of spatial fragmentation, and coordinate various kinds of space. In order to simulate different optimization results and provide solutions for decision makers, three scenarios were set up in this study. Taking Yantai City as the research area, the multi- objective programming model was chosen to carry out the study of land spatial optimization under three kinds of planning in 2020. By using the optimization model, land space efficiency has been significantly improved, with agricultural, urban, and ecological space values increased by $23.24 \%, 29.27 \%$, and $6.30 \%$. Agricultural, urban, and ecological space values have reached $1.17 \times 10^{9}, 1.14 \times 10^{10}$, and $6.44 \times 10^{7}$ yuan. After optimization, all kinds of spaces are reasonably distributed and spatial aggregation is increased. Spatial aggregation has reached the highest level with the value of 1.5876 in the ecological protection scenario, and the degree of spatial coordination reaches 2.5245 in the economic development scenario, which is the highest of all scenarios. The experimental results show that the optimization model in this study can effectively solve the problem of land space overlap and promote effective allocation of land space. Moreover, it can improve agricultural, urban, and ecological values in the land space and coordinate the development goals of different planning. It provides a technical support for land spatial optimization in the context of "multiple planning integration" in the future.
\end{abstract}

Key words: multiple planning integration; land spatial optimization; multi- objective programming model; genetic algorithm; Yantai City 